\title{
DIFFERENT SHADES OF LIFE: A PEDOGOGY OF LIVED EXPERIENCES
}

Rekha Shailaj

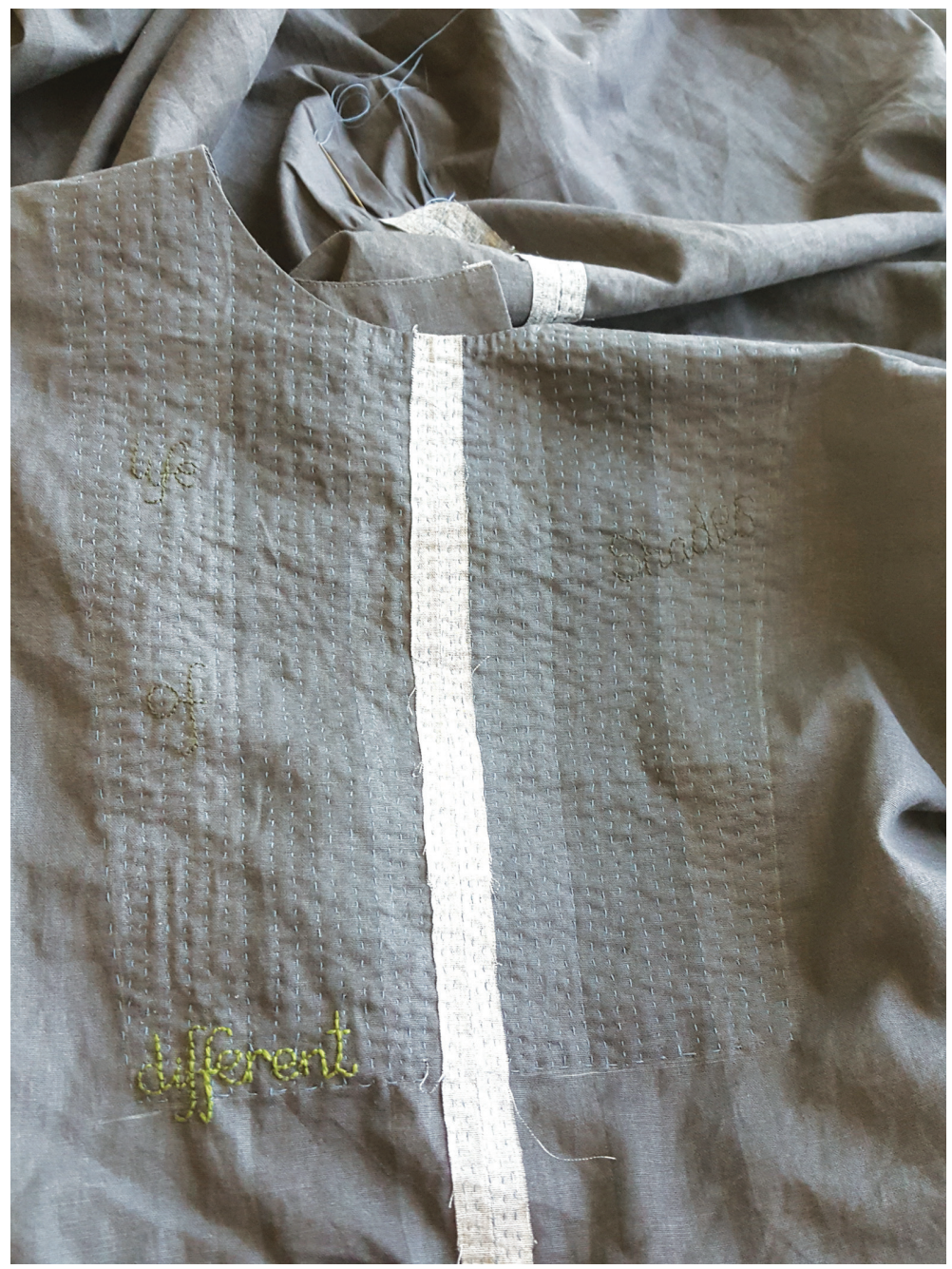

Figure I. Different shade of life dress, with embroidery and running hand stitches; a near zero-waste design. 


\section{INTRODUCTION}

There is a sense of unsettledness that some people feel as an emotion which brings them face to face with a strange method of working with their creative impulses. The research process itself becomes complex, vast and muddled. Having lived in countries other than my birthplace for the past 23 years, I have assessed my life experiences as an immigrant, traveller, nomad and a restless global citizen. I was born in India and immigrated to New Zealand in 1996. Since then, I have travelled to the Middle East twice to live with my husband and returned back to New Zealand, my adopted homeland. My research is grounded in personal experiences of living as a migrant, traveller and a nomad. In this body of work, The Different Shades of Life, I aim to unfold my life within my spatial existence constituted by the "Third" space: "The notion 'Third' refers to the constructing and re-constructing of identity, to the fluidity of spaces, to the space where identity is not fixed and as such is a feature of any kind of spatial existence."' Homeland, lived experiences, movement across spatial boundaries are some of the key ideas that embody the dichotomy of placement/displacement that I have used to conceptualise my design practice. I am aware that I exist and live my life in the "Third" space, where I feel unsettled and settled at the same time.

As a researcher, I want to make sense of the world I live in, the knowledge I gain from my experiences, and the social reality I face. These perceptions are changing as I travel the globe and seek to be settled in a place, whether it is my birthplace or somewhere other. The phenomenological human science methodology articulated and developed by Max van Manen in his book Researching Lived Experience underpins my research. I reflect phenomenologically on my lived experiences in order to grasp the pedagogical essence of meaningful experiences. The work of German-Jewish philosopher Vilém Flusser, specifically his books The Freedom of the Migrant and A Philosophy of Design, underpins my research rooted in lived experience. Flusser was a German-Jewish philosopher from Prague who fled in 1940 to Brazil where he was a professor of the philosophy of communication and wrote a daily newspaper column. In 1972, he moved to France and wrote books in both German and Portuguese.

In what follows, indented text by Vilém Flusser is followed by my interpretation and synthesis of Flusser's text into my creative work. I have contextualised my work, which lives on the cusp of differences, within Flusser's philosophy of being a migrant.

As we occupy and travel through spatial dimensions, such as our motherland, adopted homeland, faraway lands or travel routes, our experiences within each one and their phenomenological mix mark our journeys through these spaces. We become permanent travellers gathering temporal, transient experiences that come to life through the touch of a stimulus. The connectivity between these different experiences and their associated stimuli results in infinite patterns that are reflected in our lived bodies, time, space and our relationships with others. These reflections on my lived body, lived time, lived space and lived relationships underpin my research process as design practitioner.

Van Manen regards these four existential elements (lived body, lived time, lived space and lived relationships) as helpful guides for reflection on the research process. "These four existentials of lived body, lived space, lived time and lived relation to the other can be differentiated but not separated. They all form an intricate unity which we call the lifeworld - our lived world."2

As a lived body, we experience clothing through the feel of fabric on the skin, the feel of space between the garment and the body, and through the physical changes in the body. Natural materials echo the natural skin, and the lived body embraces them unconsciously. My understanding of lived time is built on my reflections on the past, present and future dimensions of my life. My lived experiences of the past surface in my present as memories and shape my future as their signification affects the choices I make in my present.

For van Manen, "the house is the location of our shared lived space, the home."' As an immigrant, I experience my lived space to extend beyond the home and homeland to connect with Flusser's concept of Heimat. For him, "the English home does not fully encompass the German Heimat, which allows for connotations such as home, homeland, and region 
(of one's origins), often accompanied by notions of nostalgia, even myths." ${ }^{4}$ Flusser believes that there is a need for us to reconfigure our houses, as they are becoming sites where the "noise" that characterises them is not translated into experience. "Experience is noise that gains meaning only in the habitual, that is, is therein transformed into information."

A house should be conceived of no longer as an artificial cave but rather as a bending in the field of interpersonal relations ... to which relationships are attracted as to a magnet. An attractive house of this sort would gather relationships, process them into information, store the information, and then forward or redirect it to others. A creative house would be a node in the network of interpersonal relations. ${ }^{6}$

The attempt to blend my Indian culture with my adopted Western culture is disrupted by my experiences of travel between the motherland, my adopted homeland and potential nomadic lands where I have lived intermittently. As a result, it is hard to mark my Heimat as a singular place. My lived relations with others form the foundation of my Heimat. This conceptual Heimat - without land, roof, floor, doors and windows - is shaped by interpersonal relationships across the globe.

"If he is not to perish, the expellee must be creative."

As a migrant it is hard to define my homeland, where I can say I have been habituated to normal surroundings or, in Flusser's words, where the blanket of habit covers and protects me. I am forced to choose the country I should live in and make my home. The motherland feels distant and alien, but so does my adopted homeland. It is hard to settle down in one place. This feeling of unsettledness has led me to retreat into my creative space, the "Third" space where my craft exists and I feel most settled and happy.

\section{EXILE AND CREATIVITY}

Here is the hypothesis I propose. The expellee has been torn out of his accustomed surroundings or has torn himself out of them. Custom and habit are a blanket that covers over reality as it exists. In our accustomed surroundings we notice only change, not what remains constant. Only change conveys information to a person who inhabits a dwelling; the permanent fixtures of his life are redundant. But in exile everything is unusual. Exile is an ocean of chaotic information. The lack of redundancy does not allow the exile to receive this information blizzard as meaningful messages. Because exile is extraordinary, it is uninhabitable. To be able to live there, the expellee must first transform the information swirling about him into meaningul messages; that is, he must process the data.This is a matter of life and death. If he is not able to process the data, he will be swamped and consumed by the waves of exile breaking over him. Data processing is synonymous with creation. If he is not to perish, the expellee must be creative?

After many years of living as a migrant my lived experiences, accumulated in my motherland, have surfaced and increasingly so as I have removed myself from that habitat. It is an extraordinary situation, where the experiences of the past are felt and relived with various extensions to the real, and hence have transformed into new entities. This directs our attention to Flusser's idea that the expellee must be creative and he must process the data. These taken-for-granted experiences surface from the past, and one feels them being lived again in new settings. According to van Manen, we appropriate the meaning of lived experiences from the past, and it is difficult to understand the depth of these experiences as they implicate the totality of life.

I regularly explore the depth of my sartorial experiences of the past specific to my Indian culture and recreate them in the present. Van Manen suggests that "lived experiences gather hermeneutic significance as we (reflectively) gather them by giving memory to them. Through meditations, conversations, day dreams, inspirations and other interpretive acts we assign meaning to the phenomena of lived life."' 
My qualitative research methodology underpins the pragmatic approach, whereby humans are capable of shaping their experiences. Their reality resides in the process that evolves and undergoes change as life unfolds itself. As a researcher, I an aware that my focus is not so much on the methods I use, but rather on the transformative nature of my design process which is informed by social reality. Hence, I find that I often need to work with a variety of research methods including reflexive, reflective, narrative/storytelling, interpretive/contextual, and iterative action approaches.

\section{EXPERIENCE}

Flusser explicates the notion of experience in relation to our passage through life. He questions whether our movements as we step out of the door and return back home through the same door constitute an experience. "We go out into the world to experience, and we lose ourselves in the process; we then return to find ourselves again, and we lose the world that we experienced."' He prods us to conceive the process of experience, not as moving from the present into the future, but instead as the future coming to meet us in our present. "We experience the world not because we move out into it but because it approaches us."10

Nevertheless, it is not simply the case that what we experience always streams in on us. In fact, we often go out and gather in what there is to experience - go looking for it. Everything that surrounds us - and we ourselves - is bathed in an unfathomable mystery, and we are able to experience only those aspects of the mystery that approach us, concern us. Ever since we have learned to think phenomenologically instead of historically, experience has become something that approaches and concerns us."

What is a lived experience? How can we understand and attach pedagogic value to a lived experience? Van Manen states that "phenomenological human science begins in lived experience and eventually turns back to it."'2 Wilhelm Dilthey explains that "the reality of lived experience is there-for-me because I have reflexive awareness of it, because I possess it immediately as belonging to me in some sense. Only in thought does it become objective."'13

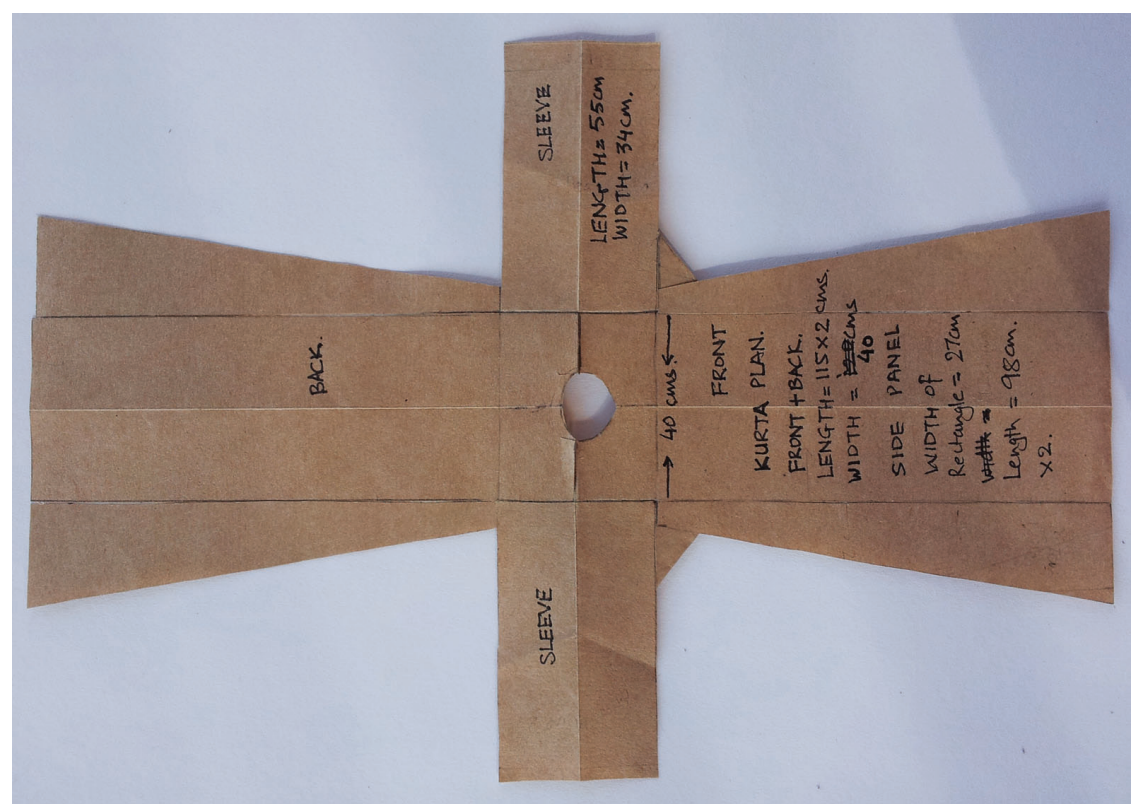

Figure 2. Top view of paper pattern for a kurta, showing panel lines and neck opening. 
Lived experiences come to life in our present when we assign them memory, reflection and meaning. Assessing and analysing my sartorial experiences requires a textual practice and a pedagogic orientation to the lived experience. Clearly, I am emotionally invested and interested in these experiences.

One such experience is that of my mother making clothes for us to wear. On reflecting back, I realise that at the time she did not use paper patterns. She calculated the measurements in her head and drew the pattern directly onto the fabric. Indian tailors and designers call this localised technique table-cutting. At the time, I could not understand her method of working. However, today I have connected with this experience and drawn from it to create fashion designs. The use of numbers and geometry is essential to this method of designing. The technique heavily relies on the use of panels. A basic rectangular shape is cut into two panels, using diagonal lines. These new shapes are trapezoids that can be rotated and swapped to join the rectangular shapes. A trapezoid is a four-sided enclosed shape with a pair of parallel sides. In Figure 2 these trapezoids are attached to the central rectangular piece and constitute the front and the back of the traditional dress or kurta. The sleeves are made up of rectangular shapes, and triangular gussets provide ease around the armhole.

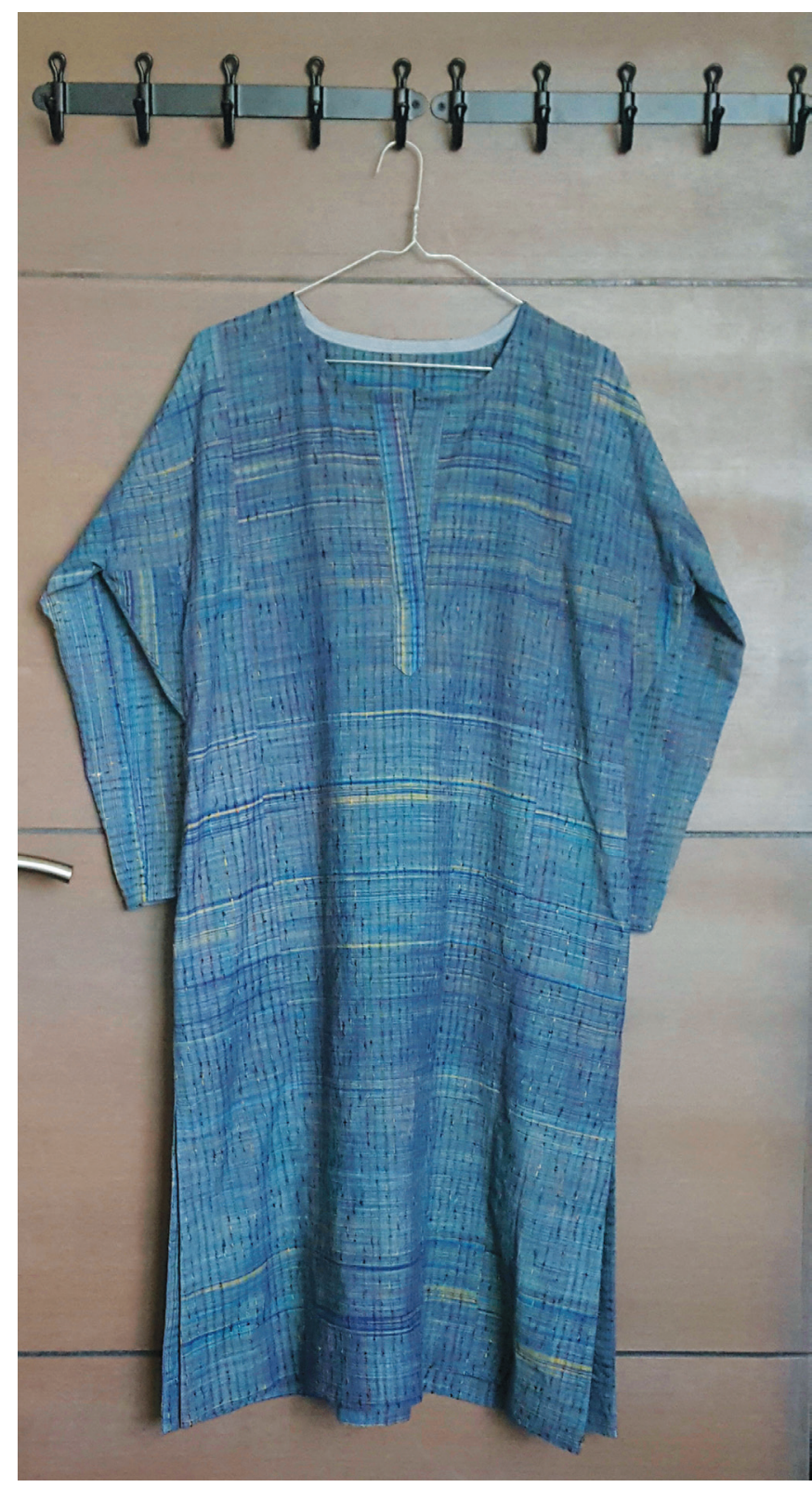

Figure 3. Kurta design with shoulder slope.

A near zero-waste design from 2019 (Figure 3) utilises a clever arrangement of different geometric shapes. The design is embedded in and inspired by past memories of wearing khadi kurtas and making an activist statement through sartorial choices. The fabric (khadi) is woven on a handloom, complete with imperfections, giving it textural value. Living away from my homeland for the past 23 years, I feel starved of these traditional Indian textiles; however, 


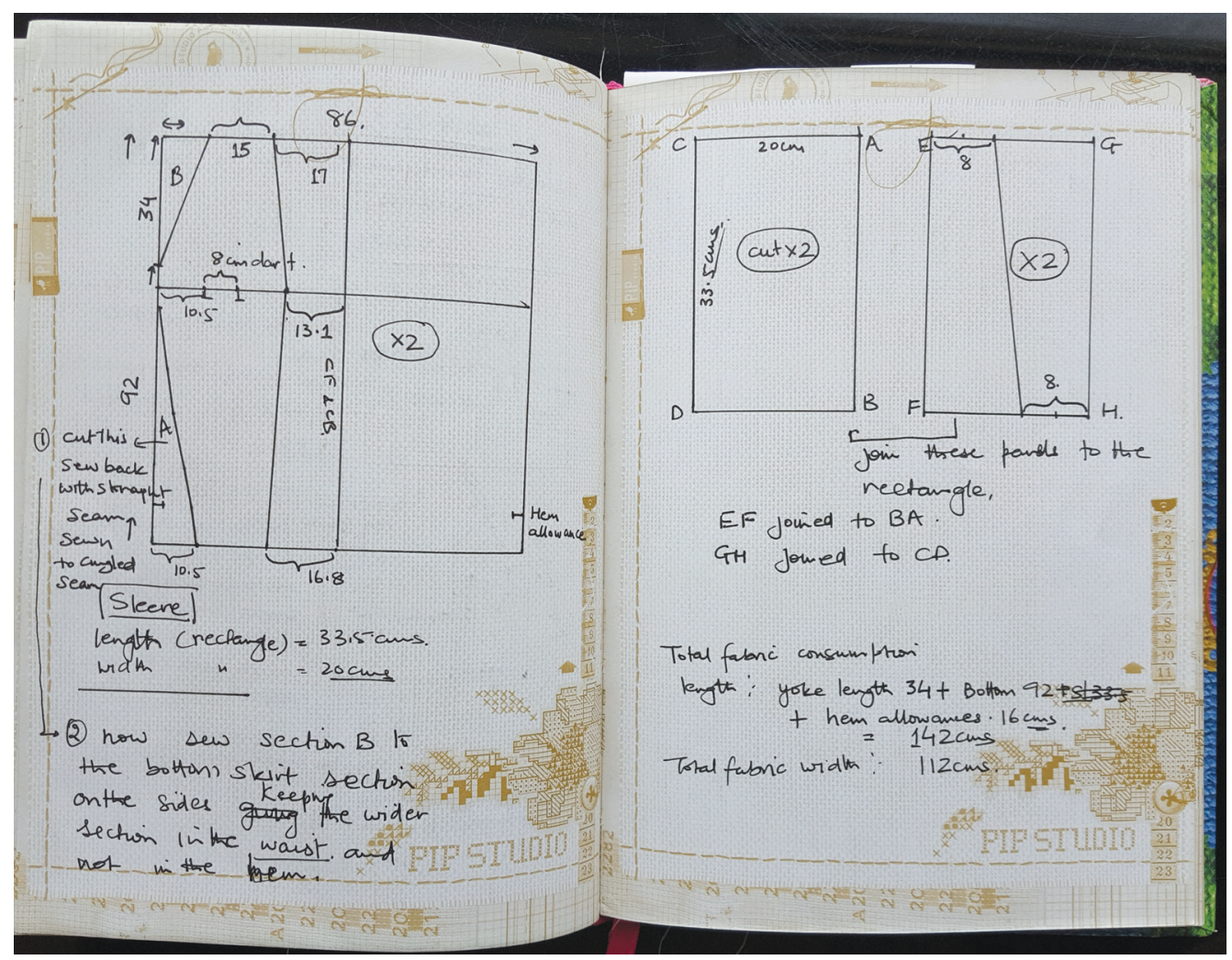

Figure 4. Detailed design notes from my design diary.

I cannot easily source these specialist fabrics today. My husband's niece gave me this fabric as a gift, several years ago. When I received it, it became one of my treasures and it took several years to incorporate it in my designs. I could have made something contemporary with it; however, I chose to use the traditional kurta design in a quest to connect to my past identity, which is still alive somewhere in the crevices of my eclectic identity. Its making was contextualised as I moved to Bahrain for a year to live with my husband. I came closer to my birthplace and visited my family in India for a period longer than usual.

Today, I have recreated the traditional look of the kurta using design methods that achieve minimum fabric wastage using techniques that are familiar to me from the days when I experienced my mother's table-cutting methods. I have now added to her techniques and transformed them, giving them a special character. Citing Dilthey, van Manen states: "Lived experiences are related to each other like motifs in the andante of a symphony. Dilthey talked about 'structure' or 'structural nexus' as something that belongs to a particular lived experience (something like a pattern or unit of meaning), which becomes part of a system of contextually related experiences, explicated from it through a process of reflection on its meaning." 14

The only limitation of the kurta design is the lack of shoulder slope. As soon as the shoulder slope is built into the design using traditional patternmaking techniques, it creates wastage of fabric. However, the use of clever geometry allows for a shoulder slope and neck opening without fabric wastage (Figure 5). I have developed many designs using this technique, involving playing with the diagonal cut line that echoes the shoulder slope by rotating and swapping the left/right and front/back panels (Figures I, 5, 6 and 8). 
The designs become more complex as the panel lines increase in number and as the sleeves, pocket bags and facings are cut using the panelling technique. This method of designing is process-driven and relies heavily on a robust system of making notes, drawing scaled-down versions of design drafts, and toiling on a small scale before the design is tested full scale. Any alterations to the design drafts will produce different silhouettes. The patternmaking process depends on cutting out templates for neck and armhole openings, and draping procedures.

This design system forced me to find meaning in the method and the process. While the method and process is partly rooted in traditional ethnographic techniques, it is also dependent on innovative and scientific ways of calculating, recording, making, altering and experimenting. The iterative actions used in designing are based on both definitive figures and imaginative, unpredictable silhouettes. This underlines the need to engage in many design iterations to find different solutions.

\section{WE NEED A PHILOSOPHY OF EMIGRATION}

Humans are contingent beings because their movements are directed along certain pathways by natural and cultural things in their surroundings. To be contingent means being surrounded by things that steer the movement of the contingent being along certain pathways. There is in their surroundings one place without things. This place that is free of things may be called the ironic. When we take an ironic stance, we are afforded a clearer view of our contingence. The movement into irony is an act of outrage. And with this motion a person rises above contingence. Movement away from irony is a form of engagement. With this motion the person returns to his state of contingence to change it. These two movements taken together are called freedom. I could also call this outrage in irony "emigration" and the reverse movement out of irony (engagement) "immigration." ... in my outrage I emigrate out of one contingence to immigrate into another, but my emigration is not only a matter of outrage; it is also a form of flight. Is a person free simply because he is able to flee? ${ }^{15}$

As an emigrant and immigrant, the pathways I left and chose 23 years ago are still partially contingent. The circumstances of that contingence are always in flux, seeming to transform with the passage of time. The feeling of normalcy that comes with permanence is missing. The roots that ground you in a place are weak. It is the irony of being faced with the possibility of another round of movement that causes one to vacillate from an emigrant to an immigrant position, that makes a contingent being more of a nomad. To choose another homeland is possible only under certain circumstances, and to return to the existing one is dependent on how well one can adapt to changed circumstances. Both options are fraught with contingencies. This practical stage of taking flight from and landing in multiple homelands (all different in some respects) creates a sense of unsettledness. Do I have the potential to make something out of this unsettledness? While the "natural things" that Flusser identifies keep me grounded in any chosen homeland, the different "cultural things" push me into the in-between spaces, the interstices where I find comfort in unsettledness. Following an ideology that explains the expelled, unsettled being, I work with contradictions and conflicts, such as traditional/unconventional, original/borrowed, clarity/ambiguity, high/low. Flusser point out that "we are all expellees to the extent that we unsettle ourselves, when our seatedness in habit is continually exorcised." 16

When I engage in fashion design, my work is generally informed by nostalgia for my motherland and its traditional clothing, textiles and techniques. These original design references transform into unconventional outcomes as I start applying borrowed ideas from different lived cultures. Consequently, the design process becomes complex and ambiguous. Unless I stop and articulate it, the sense of vagueness intensifies.

The design process transcends the non-availability of traditional tools. It adapts to unconventional materials and processes such as paper in place of fabric, hand-sewing in place of machine-sewing and draft notes in place of paper patterns. The complexity of visualising different shapes and forms according to geometry informs the design process. Practical movements, such as displacing, swapping, rotating the different components of a design ensemble, are used 
as a technique to alter the form and shape of clothing design. As a result, the designs are different and strange to the wearer.Wearers react with confusion - this is not normal experientially. These designs are not rooted in convention, tradition and sartorial norms. It is almost as if they are seeking references to and appropriation of elements from different cultures and echoing the unsettledness that I experience as a global dweller.

My garment designs resemble the silhouettes of objects such as sacks, tents, barrels and bubbles. They allow for the body, space and the garment to be experienced by the wearer in their phenomenological existence. I wear my 'tents' when I want to be comfortably moved between spaces, distance, time, 'sacks' when I want to hide from the external gaze, and 'bubbles' when I am experiencing temporality.

The design process for my dresses (Figures 5-8) started with sourcing fabrics. I discovered the fabrics in a huge pile of discounted cotton bedsheets in a supermarket. I started to deconstruct these fitted sheets by unpicking the seams and the elastic sewn into the seams. The focus moved to repurposing these nearly thrown-away bedsheets. The organic move of unpicking lent itself to hand-sewing stitches, raw unfinished edges, the repurposing of the discoloured edges as trims and hand embroidery as key elements that became integral to the designs.

As my research progressed towards the concept of preservation, restoration and upcycling, my designing followed the path of emotional engagement with my experiences and memories of making ethnographic clothing and craft. The reconditioned textiles were transformed into panelled dresses with different silhouettes including tents, bubbles and cocoons. My aim was to use the material with near-zero wastage. As designing progressed, new techniques involving the use of geometric shapes and angled lines developed to conserve the fabrics.

As I move further into the realms of unsettledness, it is the act of self-preservation that most clearly articulates the narrative of sustainability.

\section{CONCLUSION}

Do I seek to be bound by the Heimat and a concomitant sense of rootedness, or liberated from my Heimat into unsettledness? My design methodology thrives on the creativity that comes with the freedom of an immigrant who weaves her connections with others, occupies her "Third" space and surrounds herself with conscious temporal experiences. It is the dichotomy of settled and unsettled state that is important for my creative work. While creativity resides in the "Third" space of the Heimat, and it is very settling to be creative, this creativity is born of the unsettled state. This creativity is alive, transforming and never settled. As I keep travelling in an unsettled state seeking the Heimat, I will only be settled through my creativity. As Flusser states, the expellee should have the potential for making something out of their unsettledness. As a creative designer, I seek the habitual associations of the known home so that I can receive "noise" as "information," and so that I can produce information even though my Heimat has become conceptual and formless. 


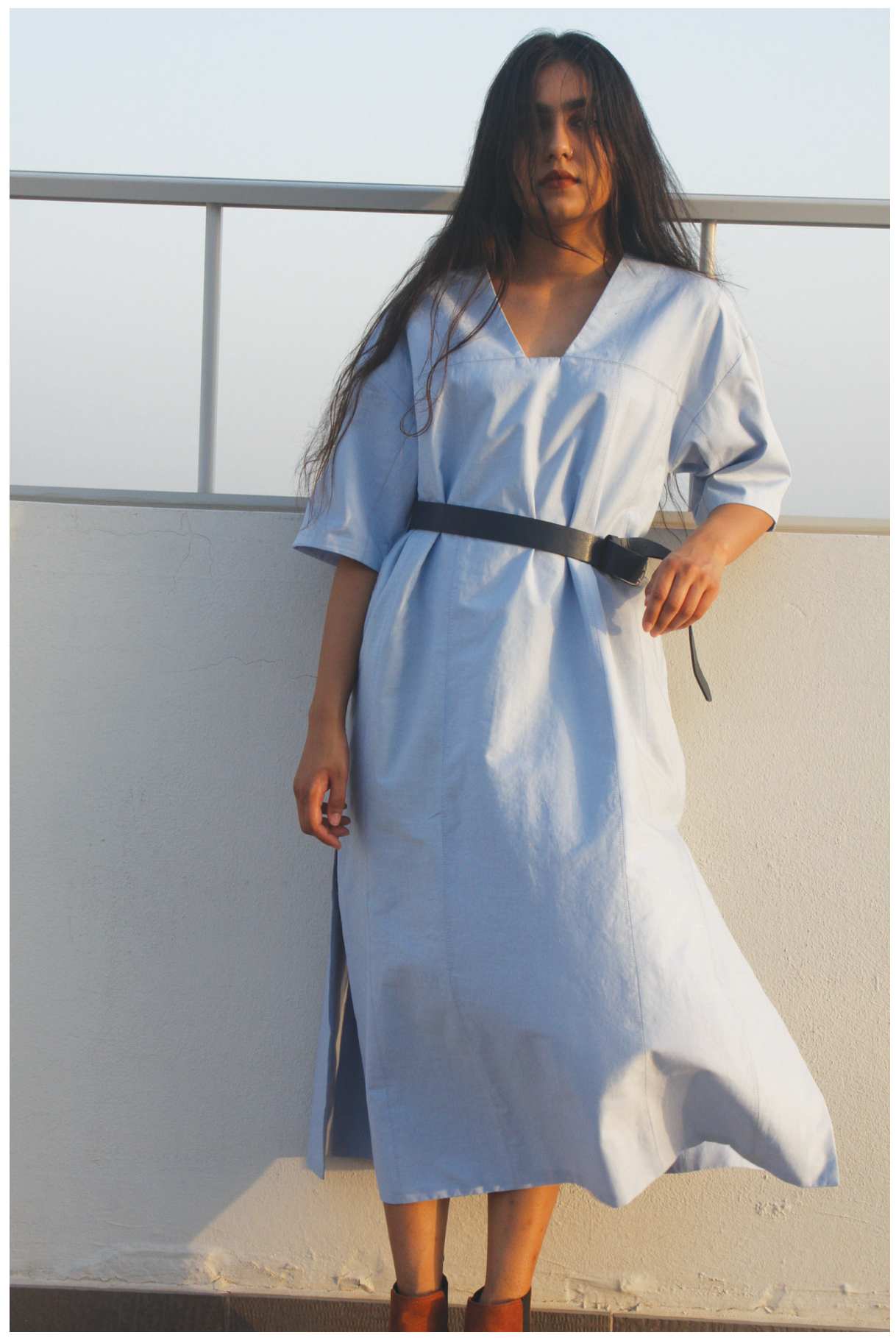

Figure 5. Long kurta dress with near-zero fabric wastage;

what wastage there is derives from the marginal sleeve-head shaping. 


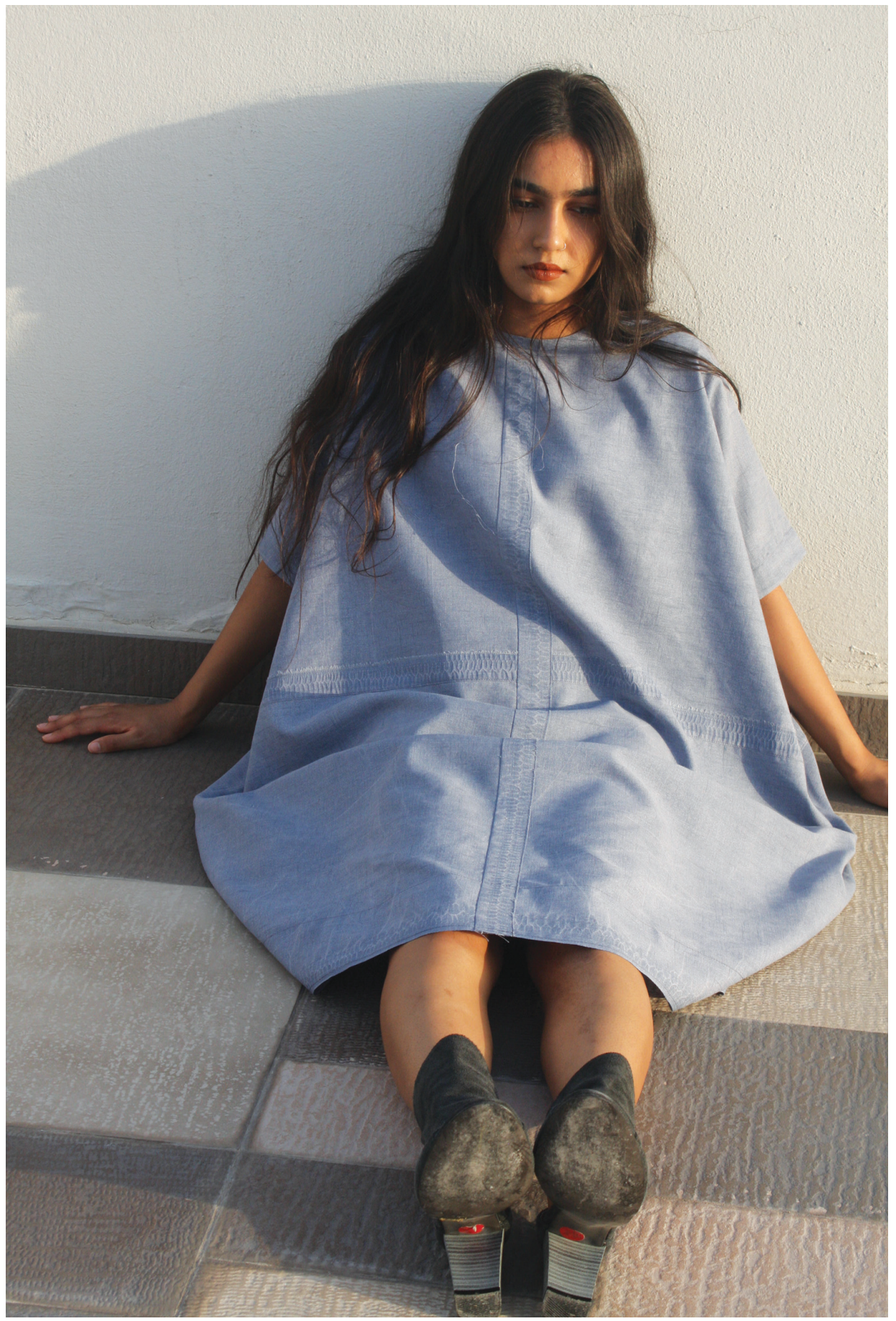

Figure 6a.The Cocoon dress (front and back views), a near zero-waste design; any waste occurs at the neck opening. 


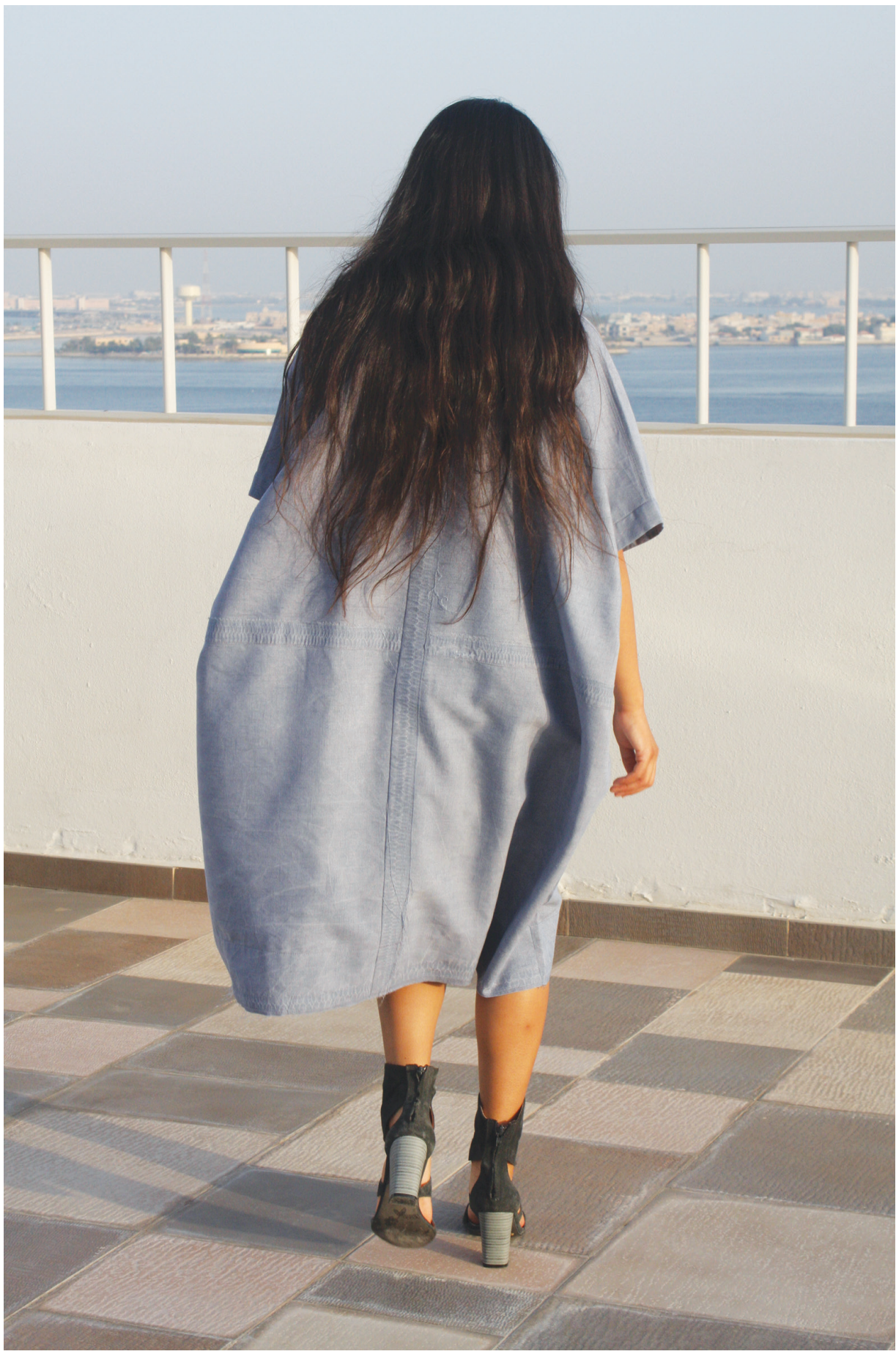

Figure 6b.The Cocoon dress (front and back views), a near zero-waste design; any waste occurs at the neck opening. 


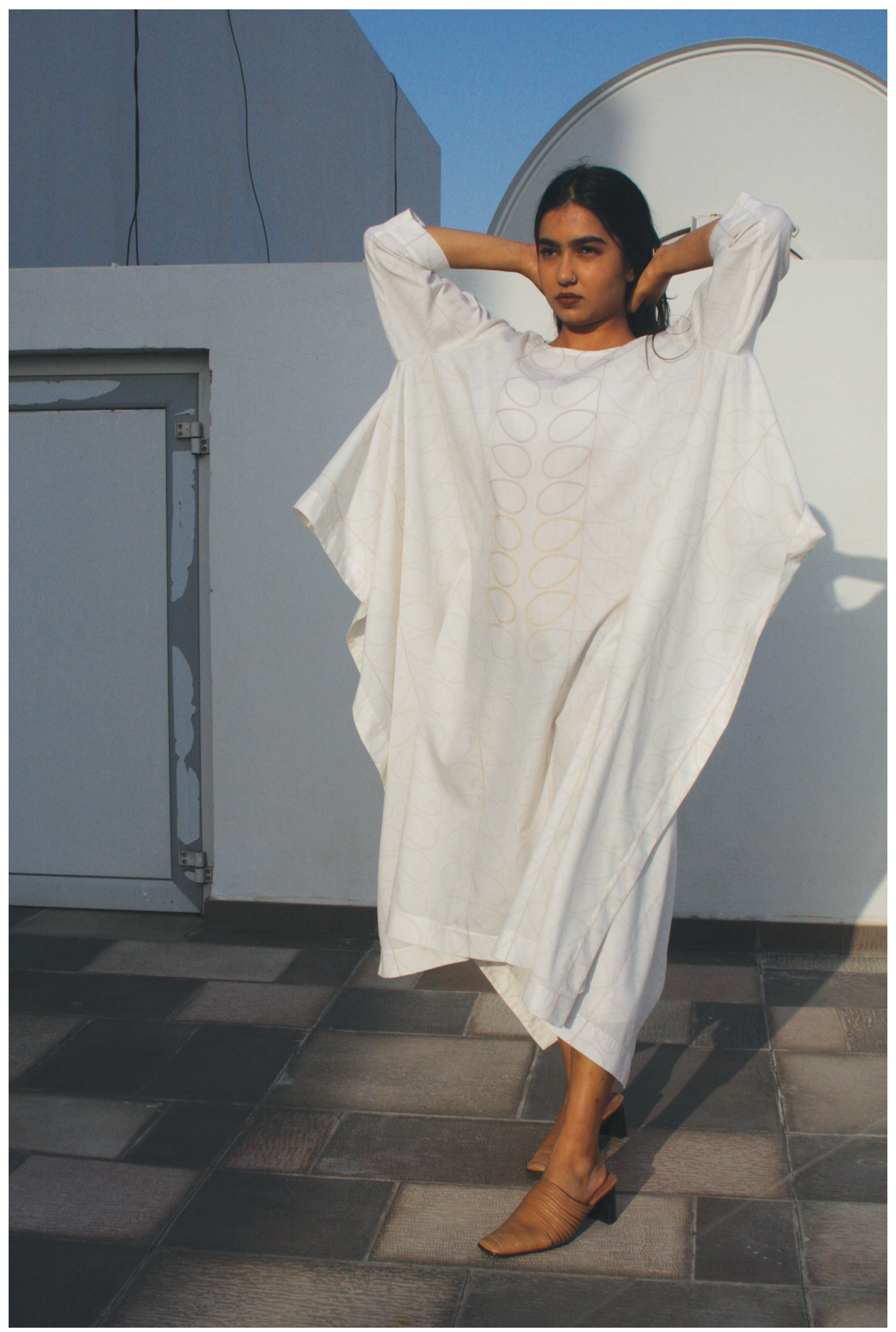

Figure 7a. The Tent dress, with embroidered front panel and open side seams. Near zero-waste design. 


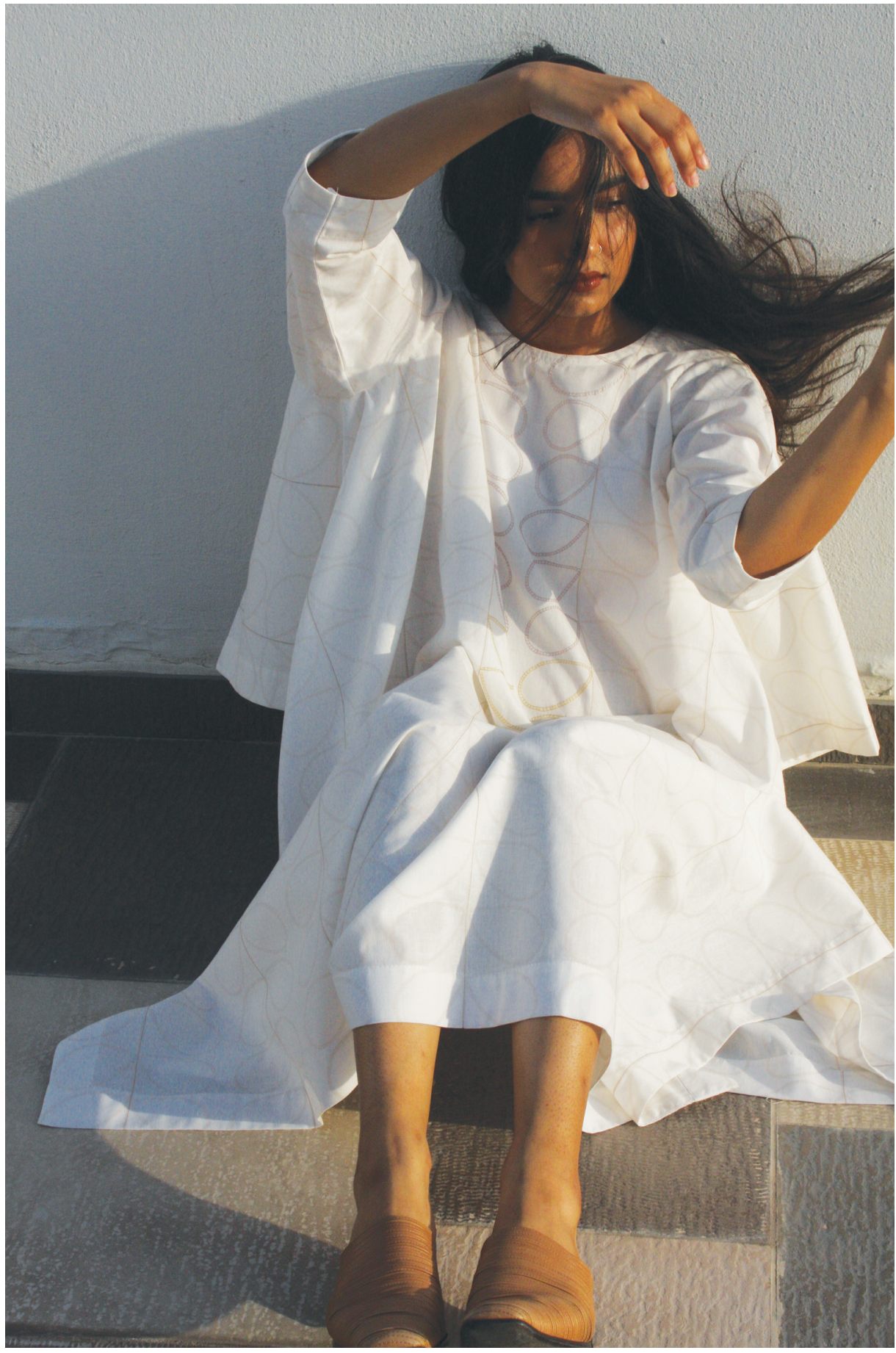

Figure 7b. The Tent dress, with embroidered front panel and open side seams. Near zero-waste design. 


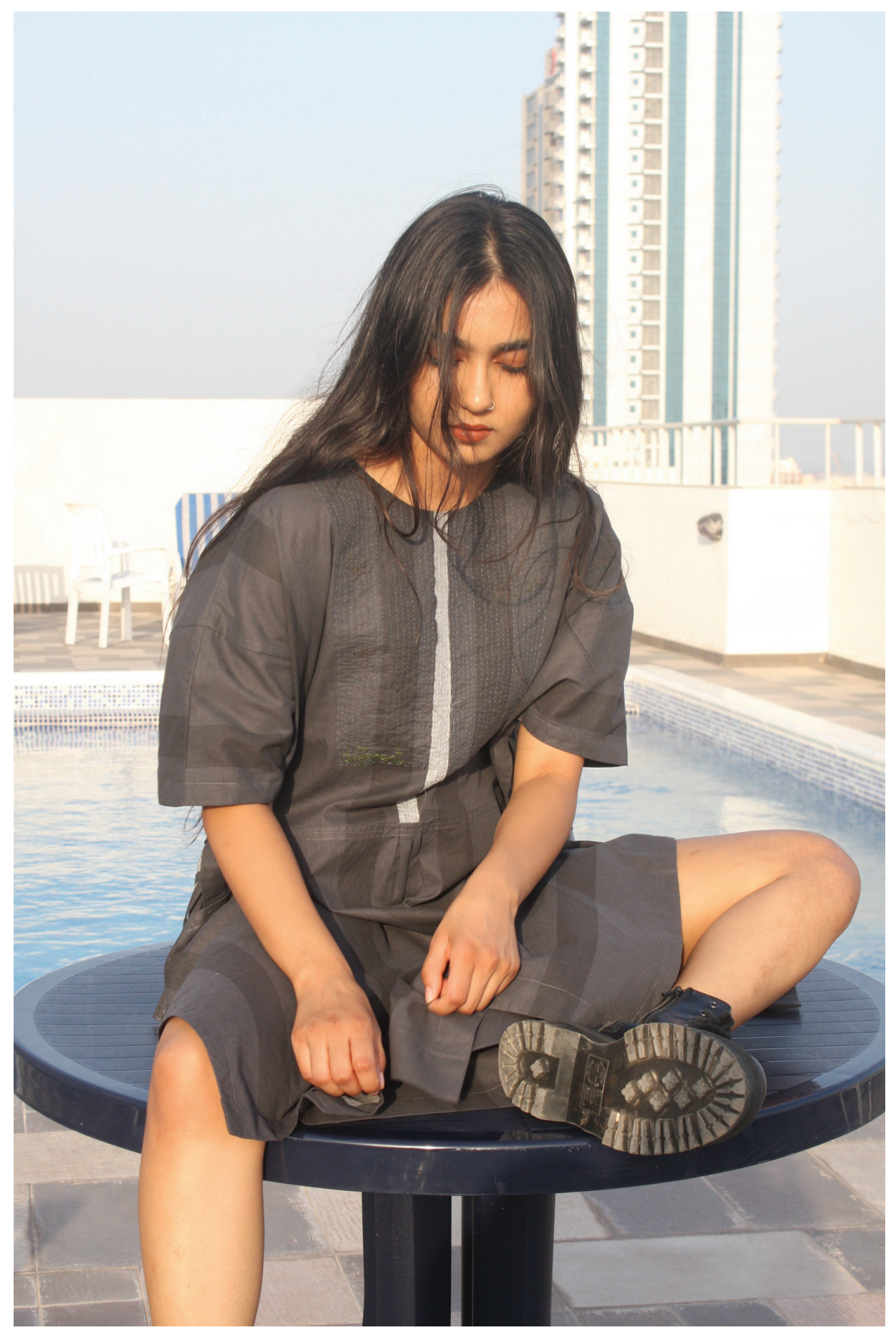

Figure 8. The Different shade of life dress, showing the long side slits. 
Rekha Rana Shailaj is a Senior Lecturer at School of Design, Otago Polytechnic teaching on the Fashion programme. Rekha graduated with a Diploma in Design (Fashion) from Otago Polytechnic in 1997 and completed a Master of Fine Arts (Design) with distinction in 20II from the Dunedin School of Art, Otago Polytechnic. As a conceptual designer, Rekha practices design in a multicultural environment, working with subjectivities and identities created through different fashion systems, drawing on both Eastern and Western sensibilities. Ethnographic clothing is an area of special interest, especially from India where she was born and raised. Her current research focus is on working with traditional clothing from India and extending the construction methods to create near zero waste fashion outcomes.

I Edward W Soja, Thirdspace: Journeys to Los Angeles and Other Real-and-imagined Places (Cambridge, MA and Oxford, UK: Blackwell, 1996).

2 Max van Manen, Researching Lived Experience: Human Science for Action Sensitive Pedagogy (London and New York: Routledge, 20।5), 105.

3 Ibid., 106.

4 Vilém Flusser, The Freedom of The Migrant (Chicago, ILL: University of Illinois Press, 2003), I.

5 Ibid., 55.

6 bid., $55-6$.

7 |bid., 81.

8 van Manen, Researching Lived Experience, 37.

9 Flusser, The Freedom of the Migrant, 65.

10 Ibid., 66.

II Ibid., 69-70.

12 van Manen, Researching Lived Experience, 35.

13 Wilhelm Dilthey, Selected Works, Vol. 5: Poetry and Experience (Princeton, NJ: Princeton University Press, 1985), 223, quoted in van Manen, Researching Lived Experience, 35.

14 Dilthey, Poetry and Experience, 227-8, quoted in ibid., 37.

15 Flusser, The Freedom of The Migrant, 21 -3.

16 Ibid., 27. 